\title{
ARTES MARCIALES. LA GUERRA Y LA IDENTIDAD COLECTIVA
}

\author{
MARTIAL ARTS. WAR AND COLLECTIVE IDENTITY
}

Jacinto Choza

Universidad de Sevilla (España)

Recibido: 20-05-2012

Aceptado: 26-06-2012

Resumen: En este artículo se expone el origen de las artes marciales y el deporte a finales del paleolítico, y la escisión entre las armas y las letras y su alianza a lo largo del neolitico. En segundo lugar se expone la relación entre agresividad, violencia y justicia y la elaboración de los valores políticos y militares como clave de la identidad colectiva. Finalmente se explica el renacimiento de las olimpiadas y la globalización del deporte como modalidades de afirmación de la identidad colectiva.

Palabras-clave: Artes marciales, deporte, pacifismo, identidad colectiva.

\begin{abstract}
This paper explain the origin of sports and of martial arts at the end of paleolithic, and the Split between writings and weapons snd its Alliance in the neolithic. In second terms it explain the relation between agresivity, violence and justice and the formation of political and military values as key of colective identity. Finaly explain the renaissance of Olympique Games and globalization of the Sport as a way of afirmation of colective identity

Key-words: Martial arts, sport, pacifism, collective identity.
\end{abstract}

\section{Origen de las artes marciales y el deporte.}

$\mathrm{Al}$ parecer, la caza fue el medio de supervivencia más importante del sapiens, desde su salida de África hace unos 100.000 años y su extensión por toda Eurasia, a pesar de que se alimentara también habitualmente de raíces y otros vegetales, y ocasionalmente de carroña.

Los procedimientos de la actividad venatoria se utilizan también para las luchas entre tribus rivales cuando tenían lugar, y esos mismos procedimientos se desarrollan como actividad lúdico-religiosa, de culto a los poderes 
sagrados, en las honras funerarias, y como actividad deportiva, entre las tribus de cazadores recolectores paleolíticos y entre los cazadores recolectores actuales.

La guerra propiamente dicha, como actividad que requiere una programación y ejecución prolongada, se inicia en el neolítico, no antes del milenio 10 aC., según sostienen pre-historiadores y antropólogos, entre ellos Marvin Harris. Cuando empieza el neolítico, hace tiempo que las actividades venatorias y bélicas se han autonomizado respecto de la religión, y hace tiempo que, emancipadas de su interés y de su rendimiento práctico inmediato, se han convertido en artes, o lo que es lo mismo, en deportes y juegos. Pero estos juegos no han perdido del todo su carácter religioso ni la memoria de su nacimiento vinculado a la supervivencia de la tribu.

Por eso, cuando en el siglo VIII adC., se instituyen en Grecia las grandes celebraciones de los juegos Olímpicos, Píticos, Ístmicos y Nemeos, todos se celebran como ceremonias religiosas. En esas ceremonias se ensalza la dignidad de la caza y de la guerra, y se elaboran narrativa y poéticamente sus comienzos, como aparece en las Odas de Píndaro, y en otros relatos. En concreto, en el Timeo, al referir el mito de la Atlántida, Platón expone el trabajo de Heracles para salvar Atenas de sus invasores y constituir la ciudad sobre un fundamento estable de paz, que permita la vida digna, la vida propiamente humana, que ciertamente incluye el pensamiento y la sabiduría.

Desde las primeras elaboraciones míticas, literarias y filosóficas, desde Píndaro y Platón, la fuerza y la destreza físicas se establecen como fundamento de la vida humana digna y de la vida intelectual

En los juegos de la Hélade, sobresale como prueba máxima el Pentatlón, que reúne las cinco actividades clave de la caza y el combate de los primeros sapiens, a saber, el lanzamiento de disco, el lanzamiento de jabalina, el salto, la carrera y la lucha. En esos juegos destaca sobre todos la figura de Milón de Crotona ${ }^{1}$, a quien se le supone casado con la hija de Pitágoras, el más sabio de los sabios de Grecia.

\section{Las armas y las letras.}

Tanto Croton como Pitágoras, aunque probablemente son personas reales, son asimismo figuras con biografías reelaboradas míticamente, también en lo que se refiere a su parentesco y estrecha amistad y colaboración. En esa relación se expresa la vinculación e incluso la unidad de la fuerza y la sabiduría, que constituía el ideal de la paideia griega, y que se recoge en el culto a Palas Atenea, la diosa de la guerra, la civilización, la sabiduría, la estrategia, las artes, la justicia y la habilidad.

[1] http://en.wikipedia.org/wiki/Milo_of_Croton

THÉMATA. Revista de Filosofía, $\mathrm{N}^{\circ} 48$ julio-diciembre (2013) pp.: 25-35 doi: 10.12795/themata.2013.i48.02 
Inicialmente, la sabiduría práctica no está separada de la sabiduría teórica en el mundo griego ni en ninguna otra cultura, ni la fuerza de la inteligencia, ni la guerra de la justicia y la verdad. Es el incremento demográfico y la división del trabajo lo que genera esas separaciones, pero también cuando eso ocurre las habilidades diferenciadas vuelven a reunirse en la educación completa de los jóvenes. Así aparece también en los ideales del humanismo romano, y en los del humanismo de todas las grandes culturas hasta el siglo XX.

En efecto la unidad de la fuerza y la sabiduría emerge en sus diferentes versiones como unidad del santo y el guerrero en los héroes de los cantares de gesta y de las sagas, en las órdenes de caballería como los caballeros templarios y otros, como unidad de las armas y las letras en el ideal cervantino del barroco, en el guerrero chino y en el samurai japonés, en el oficial y caballero de los ejércitos modernos y contemporáneos, y se mantiene incluso en el siglo $\mathrm{XX}$, en el kamikaze en el mártir de la jihad, cuando ya la guerra ha sufrido una transmutación en holocausto destructivo que la hace incompatible con cualquier tipo de ideal heroico y de sabiduría.

Siempre hay un código del honor para el guerrero, una disciplina ascética, una piedad, una caballerosidad, un espíritu de servicio y una generosidad, cercana a la de los sacerdotes que ofrecen los sacrificios, como expresión de que el guerrero mismo es también la persona que se ofrece en sacrificio. Así queda recogida en la famosa película de Akira Kurosawa "Los siete samurais", que recoge una tradición griega de Los siete contra Tebas de Esquilo, y que mantiene un influjo recíproco continuo con John Ford.

Por otra parte, en el mundo occidental e igualmente en las culturas orientales, también la sabiduría se despliega como una lucha heroica, tanto en su versión científica como en la artística. En efecto, el científico, desde Pitágoras y Posidonio, pasando por Magallanes y Elcano, hasta Darwin y Pasteur, es un explorador, un aventurero audaz, que también está dispuesto a jugarse la vida por el saber y a afrontar una aventura en solitario.

Ese carácter de explorador y "guerrero"solitario que siempre ha tenido el científico, ha sido también un rasgo del artista, especialmente en el romanticismo. Pero ya desde los tiempos de Fidias y Praxiteles, de Miguel Ángel y Velázquez, el artista es también un sabio, un explorador, un combatiente, un caballero y un héroe, y aspira a ese reconocimiento desde los inicios de la modernidad en occidente, hasta su apoteosis con Baudelaire y Van Gogh, con Picasso y Stravinski.

Por eso, a veces, como el guerrero y el militar, el científico y el artista es también un mártir, y a todos la comunidad les rinde el mismo tributo de conservar su memoria en mausoleos, memoriales, plazas, avenidas o centros educativos e institucionales en general. 


\section{Agresividad, violencia y justicia.}

Adentrarse en territorio ignoto, en tierra de nadie, y conocer, eso, es explorar, averiguar, conquistar, volver a casa con el botín, enriquecerse y enriquecer a los del propio pueblo. Aquí el lenguaje mantiene su doble sentido en relación con realidades materiales, físicas, y con realidades inmateriales, conocimientos. Porque la conquista en ambos sentidos es hacer proseguible la vida, domesticar el caos y traerlo a casa sumiso, es decir, hacerlo habitable, componer el cosmos. Esa fue la tarea civilizadora de los primeros sapiens, a algunos de los cuales la memoria épica del neolítico les dio el nombre singular y divino de Heracles.

Ese es el sentido de la agresividad, de la violencia, reducir el caos a cosmos, conducir lo inhumano a lo humano. La agresividad y la violencia, desarrolladas y ejercidas en ese sentido, se constituyen en una virtud a la que los griegos llamaron andréia, los romanos fortitudo, y los españoles fortaleza y también valor. Se constituyen en un conjunto de virtudes, entre las que se cuentan la audacia, la valentía, la magnanimidad, que se consideraban propia del andrós, del varón, porque es quien practicaba la caza y la guerra.

Esas cualidades eran virtudes porque configuraban del mejor modo posible, con vistas al mejor rendimiento posible, un conjunto de fuerzas e impulsos naturales, propios de todos los animales, al que los griegos denominaron thymós, los romanos appetitus irascibilis y la psicología moderna agresividad.

Ese impulso radical, natural y originario de los animales, ese impulso a vivir, especialmente cuando se presentan dificultades para hacerlo, se manifiesta como desencadenamiento de una pasión que los latinos y los españoles denominamos ira, y que Aristóteles consideró que se desencadenaba sobre todo ante la injusticia. La ira es el sentimiento desencadenado ante la ruptura de la Diké, de la justicia, que entre los griegos significaba tanto el orden cósmico como el orden social, y que apunta al restablecimiento de ese orden cósmico y social, ese orden que consiste en reconocer a cada uno lo suyo y restituirselo para que puede seguir existiendo, seguir viviendo de un modo humano.

Por eso, el que establece la justicia, las condiciones en que es posible y digna la vida, no son solamente los que dictan las leyes y organizan la convivencia social, como Solón y Pericles, sino también los que domestican al caos y ponen brida a la violencia destructiva, al mal, lisa y llanamente, como Heracles y Epaminondas, como Milón de Crotona y Pitágoras.

Por eso los militares y los triunfadores de los juegos merecían ser venerados como dioses. Por eso Píndaro los venera así. Porque sobre su esfuerzo y su poder, su saber y su ingenio, se construye la justicia, y sobre la justicia se establece la vida que es y merece llamarse humana. 


\section{La guerra y la identidad colectiva.}

Vico había observado que todos los pueblos y todas las culturas tienen su Heracles, su dios de la ingeniería, y su Martes, su dios de la guerra. Pero no como dioses lejanos sino como progenitores. Porque cada pueblo es el que es y los individuos en su conjunto son lo que son gracias a Heracles y a Martes, gracias a los héroes.

Antes de la expansión del imperio a todo el occidente europeo, antes de la fundación de sus ciudades en esos territorios, los romanos conocen entre esos pueblos varios tipos de vinculación de los guerreros con sus jefes, de entre los cuales adoptan uno que es la institución a la que dieron el nombre de Devotio iberica.

La Devotio ibérica es una institución por la cual un guerrero se vincula a su jefe mediante el juramento a un dios y le ofrece su vida al dios a cambio de la de su jefe. El dios protege la vida del jefe tomando a cambio la del guerrero, y el guerrero protege la vida del jefe en el combate a costa de la suya, e incluso se inmola con el jefe si muere. El jefe queda obligado a proporcionar protección y algunos medios de vida y de lucha al devoto. Se trata de una institución análoga a la clientela romana, y a otras existentes entre los galos y los germanos. Lo distintivo de la Devotio ibérica era su radicalidad, el vínculo de vida y muerte.

Los romanos le dieron el nombre de Devotio ibérica porque una institución con esos rasgos solo la habían encontrado en la Península Ibérica. $\mathrm{Y}$ en no pocas ocasiones la utilizaron para formar sus guardias y cuerpos especiales, a veces introduciendo algunas modificaciones en la institución. Algunos historiadores suponen que las defensas de las ciudades de Sagunto, Numancia y Calahorra frente al enemigo romano o cartaginés, se realizaron con tanta radicalidad porque mediaban entre sus habitantes y sus aliados vínculos de Devotio ${ }^{2}$.

Posteriormente, en la fase cultural del derecho abstracto, los individuos del pueblo que consagran su vida a garantizar la realidad colectiva y la identidad colectiva, son individuos a los que sus conciudadanos tributan el máximo honor.

Cicerón cree que la guerra, y especialmente la disciplina militar, es lo que lleva a cabo el tránsito de los hombres, desde lo que los romanos ilustrados llamaban el estado de salvajismo, a lo que llamaban el estado de civilización, al estado de ciudadanos.

Esos guerreros son los que merecen en sentido propio y eminente el título de ciudadano. Originariamente, es decir, en Esparta y Atenas, ser

[2] María Dolores Dopico Caínzos, La devotio ibérica: una revisión crítica, en Homenaje a José María Blázquez / coord. por Julio Mangas Manjarrés y Jaime Alvar Ezquerra, Vol. 2, 1998, Ediciones Clásicas, Madrid, 1998, pags. 181-194.

THÉMATA. Revista de Filosofía, $\mathrm{N}^{\circ} 48$ julio-diciembre (2013) pp.: 25-35

doi: 10.12795/themata.2013.i48.02 
ciudadano quiere decir ser militar, especialmente ser estratega, oficial de la milicia. En Grecia los ciudadanos son inicialmente una élite, la de los propietarios que son, a la vez, militares, tal como lo fueron los suizos y los israelitas desde su constitución como nación en la edad media y en la contemporánea, respectivamente.

Pero en Roma la milicia se universalizó al paso que se universalizaba la ciudadanía. Los habitantes de los territorios conquistados pasaban a enrolarse o a ser enrolados en las legiones y a recorrer el imperio con sus armas, sus campamentos y su disciplina militar.

Es celebre el pasaje de Estrabón en el libro III de su Geografía, en el que comenta que unos iberos, al ver a unos romanos haciendo guardia en la entrada de un campamento, se abalanzaron sobre ellos y los redujeron pensando que estaban locos. Y lo pensaban porque no podían creer que un hombre en su sano juicio pudiera hacer otra cosa que combatir o estar tumbado dentro de su casa.

La tesis de los historiadores y sociólogos de que la guerra define las realidades nacionales, y de que nada contribuye más a construir la identidad colectiva que la guerra, tiene la fuerza de un axioma. La de los griegos contra los persas, o la de los romanaos contra Cartago, y más aún las guerra civiles, como la de Mario contra Silas, la de los portugueses contra los castellanos o la de los confederados contra la unión en los Estados Unidos.

La tesis de que la milicia y la guerra es de suyo civilizadora, y la forma más alta en que se puede invertir la vida, se formula en las ciudades-estado griegas, pasa a la historia y a la leyenda como gestas y dichos de Temístocles y Pausanias y es fundamentada por Cicerón en La República.

El ejército y la milicia es la forma "natural" de vinculación de los hombres libres con la "patria" en la ciudades griegas y en la república romana, es la forma "religiosa" de vinculación de los súbditos en las monarquías e imperios teocráticos, y la forma "común" de vinculación de los súbditos con los emperadores, señores y reyes, hasta el nacimiento del estado moderno en Europa.

Desde que nace el estado moderno y se constituye la nación-estado, y más exactamente a partir de Napoleón, se establece el servicio militar obligatorio como una nacionalización de la libertad de los individuos, que responde a esos mismos ideales históricos, y que dura hasta el fin de la guerra fría en 1991.

Durante todos esos siglos, la identidad personal quedaba garantizada y reforzada por la identidad colectiva, y la milicia y la guerra en tanto que afirmación de los ideales y factores constituyentes de esa identidad colectiva, eran también el modo de afirmar y realizar la identidad personal. 


\section{El renacimiento de las olimpiadas.}

En 1986, un noble de familia y tradición militar francesa, que había dejado el ejército para dedicarse a la pedagogía, Pierre de Frédy, Barón de Coubertin, fundó los juegos olímpicos de la edad moderna con la celebración de las primeras olimpiadas en Atenas. A partir de entonces el desarrollo de las olimpiadas corre en paralelo con el desarrollo del deporte a lo largo de todo el siglo XX.

Coubertin elaboró una filosofía del "Caballero atleta", que incluía buena parte de sus ideales cristianos, fundó la Revue Athletique, la primera revista de la historia dedicada al deporte, consiguió que se incluyera la educación física en los estudios de enseñanza secundaria franceses, y que algunas de sus realizaciones fueran presentadas en los programas de la Exposición Universal de $1889^{3}$.

Estaba convencido de que el deporte favorecería la emulación pacífica entre los hombres, incluso entre las diferentes clases sociales, que quedaban homologadas en las actividades deportivas, y que desarrollaba la inteligencia y las virtudes morales. No era un pacifista. Creía que la excelencia del ejercito del imperio británico se debía a la educación física de sus oficiales y de sus tropas, y quería esa misma excelencia para el ejército francés, y que la ventaja de Inglaterra sobre los demás países en el siglo XIX se debía al desarrollo de la educación física y el deporte entre sus jóvenes.

El deporte había empezado a desarrollarse en occidente con la revolución industrial, que es cuando empieza a haber mayor concentración de población en las ciudades, y empieza a haber mucho tiempo libre para grupos muy numerosos. Paralelamente, el desarrollo de los medios de comunicación favorece la información sobre las actividades deportivas y la profesionalización del deporte, todo lo cual acontece en efecto en el imperio británico en relación con las artes marciales y actividades lúdicas de las colonias, y en general, en la Common Wealth. Todavía se percibe la huella británica en los nombres de algunas organizaciones deportivas europeas de finales del siglo XIX y principios del XX (por ejemplo, Atletic de Bilbao, Atletic Club de Milan, y otros).

Pero el debilitamiento de la nación y los nacionalismos, la emergencia de organizaciones supranacionales cada vez más poderosas, la generalización de los regímenes políticos democráticos, la autonomización de las identidades personales respecto de las identidades colectivas, y el nacimiento de las ideologías pacifistas no se produce hasta después de la segunda guerra mundial.

La primera guerra mundial ya empieza a producir la sensación de que se había producido una mutación considerable en el concepto y en la realidad misma de "guerra", mucho más decisiva que la que había producido la aparición de la tecnología del arco y la flecha.

[3] http://en.wikipedia.org/wiki/Pierre_de_Coubertin

THÉMATA. Revista de Filosofía, $\mathrm{N}^{\circ} 48$ julio-diciembre (2013) pp.: 25-35 doi: 10.12795/themata.2013.i48.02 
En efecto, cuando hace su aparición la nueva tecnología del arco y la flecha ya no es la virtud de la energía física personal, la vis romana, la que decide de qué lado se inclinará la victoria. A partir de entonces la habilidad técnica puede derrotar a la virtud. Todavía Ulises es un héroe aún siendo un arquero y destacando en su habilidad con el arco, que es en lo que pueden destacar los plebeyos frente a los señores, pero en realidad el arco de Ulises solo lo puede manejar el que tiene la fuerza física de un aristócrata porque es necesaria toda ella para tensarlo.

En la primera guerra mundial emerge una tecnología en la que la fuerza física juega un papel mínimo o irrelevante. Aparece la ametralladora, el submarino, el avión y el carro de combate, que asume el papel de la antigua caballería. Pero todavía es una guerra convencional (GC), es decir, una guerra que tiene lugar en unos campos de batalla definidos como tales, y que tiene como objeto la derrota de un ejército enemigo. Es la última de las guerras convencionales, en las que no hay armas de destrucción masiva, armas nucleares armas químicas o armas bacteriológicas.

Con la segunda guerra mundial se inaugura la guerra no convencional $(\mathrm{GNC})^{4}$, que no tiene lugar en "el" campo de batalla, no tiene como objetivo solamente la derrota de un ejército enemigo, en la que se utilizan todo tipo de armamentos, incluido el nuclear, y en la que emerge, por primera vez en la historia humana, la posibilidad y el riesgo efectivo de una destrucción completa de la especie humana y del planeta tierra.

Entonces es cuando cambia por completo la naturaleza de la guerra ${ }^{5}$, cuando se desestructura el sistema cultural que articula los impulsos biológicos personales, especialmente la agresividad, con las virtudes morales, la identidad personal, la identidad colectiva y las instituciones sociales, y cuando el deporte asume e integra una parte de los factores biológicos y culturales que antes quedaban integrados en el sistema formado por la milicia y la guerra.

\section{Pacifismo y globalización del deporte.}

$\mathrm{Al}$ acabar la segunda guerra mundial e iniciarse la guerra fría, hacen su aparición las ideologías pacifistas. En la mayor parte de los casos, los pacifismos son un rechazo indiscriminado de la guerra, el ejército, la violencia, la agresividad y todo lo relacionado con ellas, como los juguetes bélicos e incluso los relatos épicos.

Ese rechazo indiscriminado producía en algunos casos una represión, inconsciente y también consciente, de impulsos biológicos básicos como la

[4] http://en.wikipedia.org/wiki/Conventional_warfare

[5] "Changing Nature of Warfare". National Intelligence Council. 2004. Retrieved January 30, 2006; Stathis Kalyvas (2003). "The Sociology of Civil Wars: Warfare and Armed Groups". Armed Groups Project. Retrieved January 30, 2006.

THÉMATA. Revista de Filosofía, $\mathrm{N}^{\circ} 48$ julio-diciembre (2013) pp.: 25-35 doi: 10.12795/themata.2013.i48.02 
agresividad, cuyo objetivo era desde muy antiguo la formación de las virtudes de la fortaleza (andréia), la valentía, y el establecimiento del orden junto, de la convivencia propiamente humana. La represión de esos impulsos tiene efectos patógenos que no eliminan la violencia sino que a veces la empeoran, porque la despojan de sus adecuados cauces, y debilitan el sentido social y cultural de las instituciones militares, como ha señalado Hernández-Pache$\mathrm{co}^{6}$.

Pero la segunda mitad del siglo XX también trajo consigo, junto con la globalización de las democracias y de la actividad deportiva, el acceso pleno de la mujer al mundo laboral y, en general, a todos los ámbitos culturales, incluido el deportivo, y eso ha producido una reestructuración del sistema de fuerzas biológicas y psicológicas individuales, valores morales y culturales e instituciones sociales que permiten recuperar el equilibrio psicológico y cultural. Y es importante señalar esa reestructuración y ese nuevo equilibrio porque el hombre necesita saber lo que es para serlo y necesita comprender lo que le está pasando para vivir saludablemente.

En primer lugar, el acceso de la mujer al mundo laboral y a todos los ámbitos culturales, ha producido una feminización de la sociedad, que ha aportado los valores de la flexibilidad, la tolerancia, la elegancia, la amabilidad, a la vez que el mundo femenino ha acogido en sí valores provenientes de la agresividad y de la andreia, de la virilidad, como la valentía, la firmeza, la audacia, que han sido muy importantes para las nuevas tareas que tenía que desempeñar, y para las antiguas que ahora tenía que desempeñar de un modo nuevo.

Esos valores y cualidades que el mundo femenino tenía que acoger y ha acogido no podía tomarlos de modelos militares, bélicos o pugilísticos, pero sí podía tomarlos de modelos deportivos, a la vez que introducía la feminidad en el deporte, de manera que tanto el mundo masculino como el femenino resultaran mutuamente enriquecido con las aportaciones del otro.

La introducción de la feminidad en el deporte no solo ha significado un enriquecimiento recíproco con lo que el mundo masculino ha recibido del femenino y viceversa, sino también un reconocimiento de lo exclusiva y específicamente masculino y femenino, tal y como se expresan en los deportes exclusivamente de hombres y exclusivamente de mujeres, sin susceptibilidades de género (por ejemplo, gimnasia sincronizada o gimnasia individual), o también tal como aparecen esas peculiaridades en los deportes practicados por ambos, que como es obvio siempre se practican separadamente.

Por otra parte, la mayoría de participación masculina en las actividades deportivas, tanto en calidad de protagonistas como en calidad de espec-

[6] Hernández-Pacheco, J., El duelo de Atenea. Reflexiones sobre guerra, milicia y humanismo, Madrid: Encuentro, 2008.

THÉMATA. Revista de Filosofía, $\mathrm{N}^{\circ} 48$ julio-diciembre (2013) pp.: 25-35 doi: 10.12795/themata.2013.i48.02 
tadores y aficionados, es probablemente la expresión de la raíz venatoria y bélica del deporte.

El ejército se ha profesionalizado y también se ha feminizado, entre otros motivos porque una mujer puede pilotar aviones de caza tan bien como un hombre, como ocurre con los coches de fórmula uno o de los caballos. Y con eso el ejército despliega, con esos nuevos recursos femeninos, una nueva dimensión de las tareas que a partir del siglo XXI le quedan encomendadas también como son la tareas humanitarias.

Finalmente la globalización del deporte en la segunda mitad del siglo $\mathrm{XX}$, que corre en paralelo con el rechazo de la pena de muerte y de la guerra como formas de recomponer la justicia vulnerada, proporciona cauces a los impulsos individuales y a los sentimientos colectivos.

En efecto, más allá de lo que podía soñar Pierre de Coubertin, la educación física y el deporte encauza la agresividad masculina y femenina según estilos masculinos y femeninos de agresividad y de valentía, de fortaleza y resistencia, de constancia de paciencia en la consecución de objetivos adecuados y, desde luego, justos.

Pero también más allá de los ideales de Temístocles y Epaminondas, de Ciceron o de Maquiavelo, de Napoleón o de Coubertin, los griegos, los italianos o los franceses puede sentir, y de hecho sienten, reforzada su identidad personal y su identidad colectiva cada vez que sus deportistas, individualmente o por equipo ganan el tour de Francia o el Giro de Italia, el campeonato europeo o el mundial del futbol, o la copa Davis de tenis.

También los que en cada caso suben al podium, y reciben medalla de oro, plata o bronce, escuchan el himno nacional y contemplan las banderas de sus países, sienten una emoción que nada tiene que envidiar a los que recibieron antaño, y aún reciben en el presente, medallas al mérito militar o distinciones por méritos de guerra.

Es posible que actualmente nos parezcan excesivas algunas de las aclamaciones que Píndaro dedicaba a sus contemporáneos vencedores de los juegos. Ciertamente nos parece una divinización excesiva. Pero también ahora nuestros acontecimientos deportivos son anunciados publicitariamente con himnos religiosos, literalmente, motetes, cantatas y aleluias de los más grandes compositores de música sacra del pasado.

También nuestros deportistas sos puestos como ejemplo supremo para niños y jóvenes. Y esos niños y jóvenes llevan sus insignias y sus ropas y su instrumental deportivo como reliquias y como herramientas de emulación. También nuestros deportistas visitan a lo niños pobres y a los enfermos en zonas deprimidas, en hospitales y en centros convencionales. También cuando su comportamiento es deshonroso quedan marginados de la ejemplaridad pública. Probablemente con tanta o más veneración y crítica de la que soportaron los militares y santos del pasado. 
Y es posible que incluso la economía del deporte, que en líneas generales ha superado con mucho a la de las iglesias, empiece a superar también en muchos países a la de la defensa nacional.

Las artes marciales, y en general, el deporte, ha sustituido con ventaja a las diversas formas de la guerra como sistema de refuerzos y garantías de la identidad personal y de las identidades colectivas. 